\title{
Planar measurements of spray-induced wall cooling using phosphor thermometry
}

\author{
Plamen Dragomirov ${ }^{1} \cdot$ Aldo Mendieta $^{1} \cdot$ Christopher Abram $^{1} \cdot$ Benoît Fond ${ }^{1} \cdot$ Frank Beyrau $^{1}$
}

Received: 27 September 2017 / Revised: 13 December 2017 / Accepted: 18 December 2017 / Published online: 8 February 2018

(c) The Author(s) 2018. This article is an open access publication

\begin{abstract}
The wall cooling induced by spray impingement is investigated using phosphor thermometry. Thin coatings of zinc oxide $(\mathrm{ZnO})$ phosphor were applied with a transparent chemical binder onto a steel surface. Instantaneous spatially resolved temperatures were determined using the spectral intensity ratio method directly after the injection of UV-grade hexane onto the surface using a commercial gasoline injector. The investigations showed that $2 \mathrm{D}$ temperature measurements with high spatial and shot-to-shot precision of, respectively, 0.5 and $0.6 \mathrm{~K}$ can be achieved, allowing the accurate resolution of the cooling induced by the spray. The presence of a liquid film over the phosphor coating during measurements showed no noticeable influence on the measured temperatures. However, in some cases a change in the intensity ratio at the spray impingement area, in the form of a permanent "stain", could be observed after multiple injections. The formation of this stain was less likely with increasing annealing time of the coating as well as lower plate operating temperatures during the injection experiments. Finally, the experimental results indicate a noticeable influence of the thickness of the phosphor coating on the measured spray-induced wall cooling history. Hence, for quantitative analysis, a compromise between coating thickness and measurement accuracy needs to be considered for similar applications where the heat transfer rates are very high.
\end{abstract}

\section{Introduction}

The impingement of a spray onto a surface is a complex process with numerous technical applications, such as spray painting, spray cooling of workpieces and machinery or spray/wall-interaction in internal combustion engines. The surface temperature has a decisive effect on the process, because it influences the wettability of the surface and the evaporation of the liquid. In the case of combustion engines with direct injection, the development of fuel wall films and thereby the emission of soot particles is directly influenced by the temperature of the combustion chamber walls. In contrast to the initial surface temperature, it is hardly possible to measure the instantaneous change of the surface temperature due to the spray/wall interaction and hence the boundary conditions for the evaporation of the fuel wall film.

However, this temperature information is of crucial importance for the assessment of the heat transfer and

Frank Beyrau

frank.beyrau@ovgu.de

1 Lehrstuhl für Technische Thermodynamik, Otto-vonGuericke-Universität Magdeburg, 39106 Magdeburg, Germany development of simulation models. To estimate the surface temperature, thermocouples are frequently used, but these provide only point temperature information (Panão and Moreira 2009; Reichelt et al. 2002; Serras-Pereira et al. 2013). For this reason, infrared thermography-based techniques have been developed to provide spatially resolved temperature information as demonstrated by Schulz and Schmidt (2012) and Weickgenannt et al. (2011). The limitation of these techniques is that they require the accurate knowledge of the surface emissivity and that makes it very difficult to measure surface temperatures through a liquid film.

In this regard, we investigated a measurement technique based on thermographic phosphors. Phosphors are ceramic materials, normally synthesised in powder form and produced for the fulfilment of a variety of practical applications, i.e. digital screens, lighting, etc. These materials possess the primary characteristic of temperature-sensitive luminescence emission following laser excitation. By coating the phosphor to the surface of interest, the coating temperature can be remotely probed, thereby allowing in-situ application in internal combustion engines (Aizawa and Kosaka 2008; Fuhrmann et al. 2011, 2013; Husberg et al. 2005; Kashdan and Bruneaux 2011; Knappe et al. 2011). 
In phosphor thermometry measurements, the temperature information is acquired mainly by two approaches: the luminescence lifetime method and the intensity ratio method.

The first one fits an exponential curve to the phosphor's luminescence decay in time after the end of the excitation pulse, thus basically matching the temperature to a scalar. It is a technique preferred by many researchers mainly due to its high precision and accuracy as well as relatively easy setup and the considerable available database, where the temperature-lifetime characteristics of many have been reported. On the other hand, this method is limited in cases where fast sampling of the two-dimensional temperature field is required.

The intensity ratio method, as its name suggests, takes advantage of the temperature-dependent spectral change of the luminescence signal by taking two appropriate regions of the spectrum and reducing this spectral change, by means of a quotient of both signals, to a scalar. This approach is usually best implemented with two detectors and, therefore, requires a carefully assembled setup, but is especially useful where short acquisition times are needed.

For precise surface temperature measurements, the luminescence decay time method has been used in most applications, ranging from burning materials (Omrane et al. 2002), flame-wall-impingement (Brübach et al. 2007) to remote cryogenic measurements (Claus et al. 1990). For example, Yañez Gonzalez et al. (2015) used this method to measure the temperature of cooled as well as uncooled components on a combustion chamber liner and on nozzle guide vanes. Moreover, the authors could prove that the temperature detected with the phosphor coating lies between the surface and substrate temperature, demonstrating the possibility to measure close to the bond coat. Its robustness and high accuracy has been sufficiently proven.

On the other hand, the intensity ratio method has shown great potential where narrow temporal windows for capturing fast heat transfer phenomena are desired. This is the reason why this approach was particularly suitable for fluid flow temperature field measurements allowing also the possibility of simultaneous velocity field measurements as demonstrated by Fond et al. (2012) at $10 \mathrm{~Hz}$ and Abram et al. (2013) at multi-kHz repetition rates. Its potential for precise surface thermometry has been reported by other researchers. Two of the earliest applications for intensity ratio surface thermometry are reported by Krauss et al. (1994) and Goss et al. (1989). Krauss et al. (1994) managed surface temperature measurements in the range of 193-293 K with an uncertainty of $1 \mathrm{~K}$. Goss, et al. (1989) obtained an uncertainty ranging from 9 to $50 \mathrm{~K}$ for a large temperature range of $300-1500 \mathrm{~K}$.

In terms of comparative performance of the methods, Omrane et al. (2004) performed very precise and accurate temperature measurements for piston surfaces in transparent engines, with the intensity ratio (2D measurements at $0.5 \mathrm{~Hz}$ ) as well as the decay-time method (point measurements at $1 \mathrm{~Hz}$ ), obtaining 3 and $0.5 \%$ accuracy, respectively, for a temperature range of 320-870 K. Fuhrmann et al. (2013a, b) compared the luminescence lifetime and the intensity ratio method using $\mathrm{MG}_{4} \mathrm{FGeO}_{6}: \mathrm{Mn}$ also reporting an improved precision in the case of the lifetime approach.

Bizzak and Chyu (1995) used successfully the intensity ratio method to investigate the heat transfer of a hot plate cooled by an air nozzle and an accuracy of around 5\% was estimated for the heat transfer at the stagnation point calculated after temperature measurements. However, significantly higher heat transfer rates are to be expected from liquid jets than for air jets as in Bizzak and Chyu (1995) and according to our knowledge, no investigations of the wall cooling directly on the wetted side have been reported. As already emphasised, the intensity ratio is advantageous in cases of highly transient heat-transfer phenomenon. Therefore, in this study, surface thermometry measurements were performed to investigate the feasibility of the intensity ratio method for analysis of wall cooling due to spray impingement. The influence of fuel deposits, the presence of liquid films and the phosphor coating thickness on the temperature measurements were investigated as well.

\section{Experimental procedure}

\subsection{Test rig}

Steel plates were selected as test objects for the investigation of the surface temperature change to replicate the impingement of gasoline injection sprays on metal surfaces in internal combustion engines. To heat-up the steel plates to temperatures relevant for actual gasoline engine operating conditions, a heating unit with a two-part aluminium body with internal wave-shaped channels was constructed. The heater was operated with silicon oil, which was conditioned using a bath thermostat (MPCK6, Huber) and ran throughout the channels in the heating unit directly below the steel plate. To monitor the plate temperature, two K-type thermocouples were mounted in the aluminium body, $5 \mathrm{~mm}$ below the contact point of the aluminium body with the steel plate of the heater, and a third one was positioned in the oil stream.

For the demonstration of the surface temperature measurements with spray-induced wall cooling, a six-hole solenoid driven gasoline injector (HDEV 5.2, Bosch) was used. The injector was positioned approximately $30 \mathrm{~mm}$ above the coated steel plate with an inclination angle of $30^{\circ}$ so that only two of the six spray jets impinge on the coated surface. During the study, the injection pressure $p_{\text {inj }}$ and duration $t_{\text {inj }}$ were kept constant at $15.0 \mathrm{MPa}( \pm 0.2 \mathrm{MPa})$ and $1.9 \mathrm{~ms}$, respectively. UV-grade $n$-hexane (T908.1, Carl Roth) was 
Table 1 Fuel properties from (Kleiber and Joh 2013)

\begin{tabular}{lc}
\hline Parameters & $n$-hexane \\
\hline Molecular weight $[\mathrm{g} / \mathrm{mol}]$ & 86.18 \\
Density at $20{ }^{\circ} \mathrm{C}\left[\mathrm{kg} / \mathrm{m}^{3}\right]$ & 659.4 \\
Specific heat capacity $[\mathrm{J} /(\mathrm{g} \mathrm{K})]$ & 2.231 \\
Surface tension at $20{ }^{\circ} \mathrm{C}\left[10^{-3} \mathrm{~N} / \mathrm{m}\right]$ & 18.5 \\
Dynamic viscosity at $20{ }^{\circ} \mathrm{C}[\mathrm{mPa} \mathrm{s}]$ & 0.31 \\
Thermal conductivity at $20{ }^{\circ} \mathrm{C}[\mathrm{W} / \mathrm{mK}]$ & 0.121 \\
Boiling temperature at $0.1013 \mathrm{MPa}[\mathrm{K}]$ & 341.85 \\
Evaporation enthalpy at $0.1013 \mathrm{MPa}[\mathrm{kJ} / \mathrm{kg}]$ & 334.9 \\
\hline
\end{tabular}

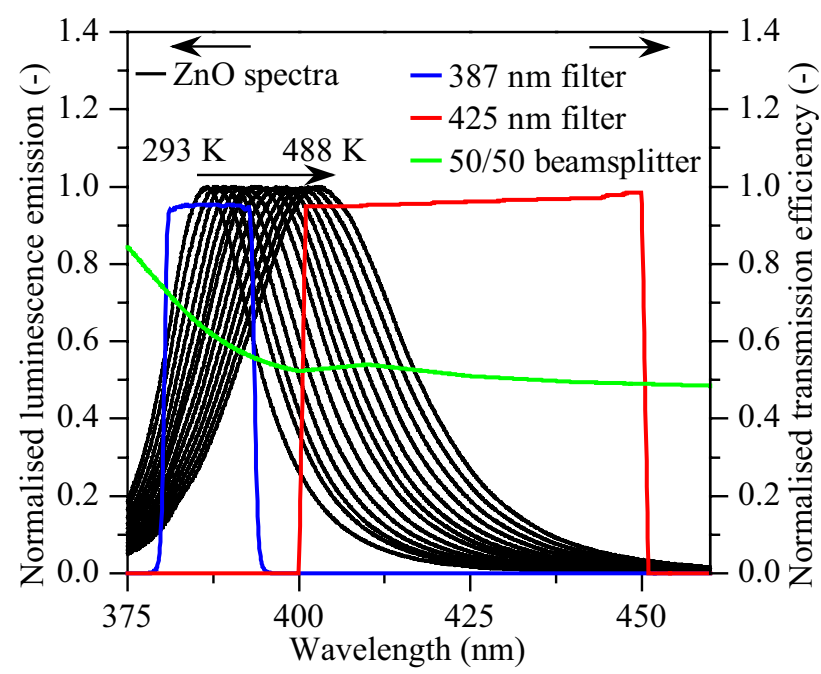

Fig. 1 Luminescence emission band of the $\mathrm{ZnO}$ phosphor particles at different temperatures plotted at $15 \mathrm{~K}$ intervals, based on Abram et al. (2015), and transmission efficiency of the optical components used in this study

used for the investigation as a gasoline substitute to avoid any interference from fluorescence from impurities. A summary of the fuel physical properties can be found in Table 1 .

\subsection{Thermographic phosphor and surface coating}

Zinc oxide particles with a particle size of around 1-2 $\mu \mathrm{m}$ (Code Nr. 96,479, Sigma Aldrich), as used in Abram et al. (2015), was the thermographic phosphor used in this work. The key factors involving the selection of this phosphor are: first, the strong temperature-dependent red-shift behaviour of the luminescence (Abram et al. 2015), see Fig. 1, resulting in a high temperature sensitivity at the target temperature range of this application - from room temperature to $500 \mathrm{~K}$ - second, a very fast response (luminescence lifetime $<1 \mathrm{~ns}$ ) suggested its viability for the ratio-based technique measurements to investigate fast heat transfer phenomena.
A mix of $\mathrm{ZnO}$ phosphor and clear binder (Ofenfarbe, ULFALUX) was sprayed using an airbrush with a double function for regulation of the air and liquid flows (type BD$128 \mathrm{P})$ onto the steel plate substrates $(0.5 \mathrm{~mm} \times 60 \mathrm{~mm} \times$ $100 \mathrm{~mm}$ ) to produce the coatings. Best results were produced with a proportion of phosphor, binder and thinner of $20 \mathrm{mg}: 4 \mathrm{ml}: 1 \mathrm{ml}$, respectively, where a thinner of type FLT 1277 (FLT Handel \& Service GmbH) was used. These components were contained in a $100-\mathrm{ml}$ beaker and carefully mixed for 3-4 min with an ultrasonic homogeniser (SONOPLUS UW 2070 with a SH70G tip, BANDELIN GmbH \& Co. KG) until a turbid, milk-like, relatively viscous fluid was obtained, before being evenly sprayed onto the substrate using an airbrush.

The thickness was determined using a simple screw-type

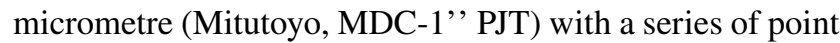
measurements in different zones of the plate. Different coating thicknesses varying from 15 to $31 \mu \mathrm{m}$ were produced, with a standard deviation of maximum 2-3 $\mu \mathrm{m}$. The results shown are all reported using the average coating thickness for each plate. The plates used in the following experiments (plates A with $15 \mu \mathrm{m}$ and B with $31 \mu \mathrm{m}$ ) were cured for about $60 \mathrm{~min}$ at $358 \mathrm{~K}$ and then heated up to $473 \mathrm{~K}$ for $12 \mathrm{~h}$ to produce a high-quality coating. Plate A was used throughout all investigations unless otherwise stated.

\subsection{Setup for surface thermometry}

The experimental setup for intensity ratio surface thermometry using thermographic phosphors is illustrated in Fig. 2. The $\mathrm{ZnO}$ coating was excited at $355 \mathrm{~nm}$ using a frequency tripled Nd:YAG laser (Quanta-Ray GCR170, Spectra-Physics) triggered at $10 \mathrm{~Hz}$. To illuminate the complete coated surface and also to decrease the gradient in the laser fluence along the investigated plate due to the Gaussian beam distribution, the laser beam was expanded using a spherical diverging lens $(f=-30 \mathrm{~mm})$. Instead of a more complex beam homogeniser (Pfadler et al. 2006), we applied a simple UV diffusor with a diffusion angle of $5^{\circ}$ (48-515, Edmund Optics) positioned in the path of the expanding beam to obtain a smoother laser fluence distribution. The laser pulse energy was monitored and kept constant during the performed experiments using an online energy monitor from LaVision at approximately $44 \mathrm{~mJ}$ for plate A, which resulted in an average fluence of $\sim 1 \mathrm{~mJ} / \mathrm{cm}^{2}$.

The luminescence emission from the $\mathrm{ZnO}$ coating was imaged by two $2 \times 2$ hardware-binned, Imager ProX CCD cameras from LaVision fitted with $85 \mathrm{~mm}$ f/1.4 Carl-Zeiss lenses, see Fig. 2, which resulted in an effective resolution of 800 by 600 pixels with a pixel scaling of $0.114 \mathrm{~mm} /$ pixel. Additionally, two bandpass filters at centre wavelength (CWL) of $387 \mathrm{~nm}$, with a full width at half maximum (FWHM) of $11 \mathrm{~nm}$, and at 425-50 nm (CWL-FWHM) were 
Fig. 2 Experimental setup for surface temperature measurements. Two cameras detect the spectrally filtered luminescence signal from the plate while a third high-speed camera is used to record the spray impingement (see Sect. 2.4)

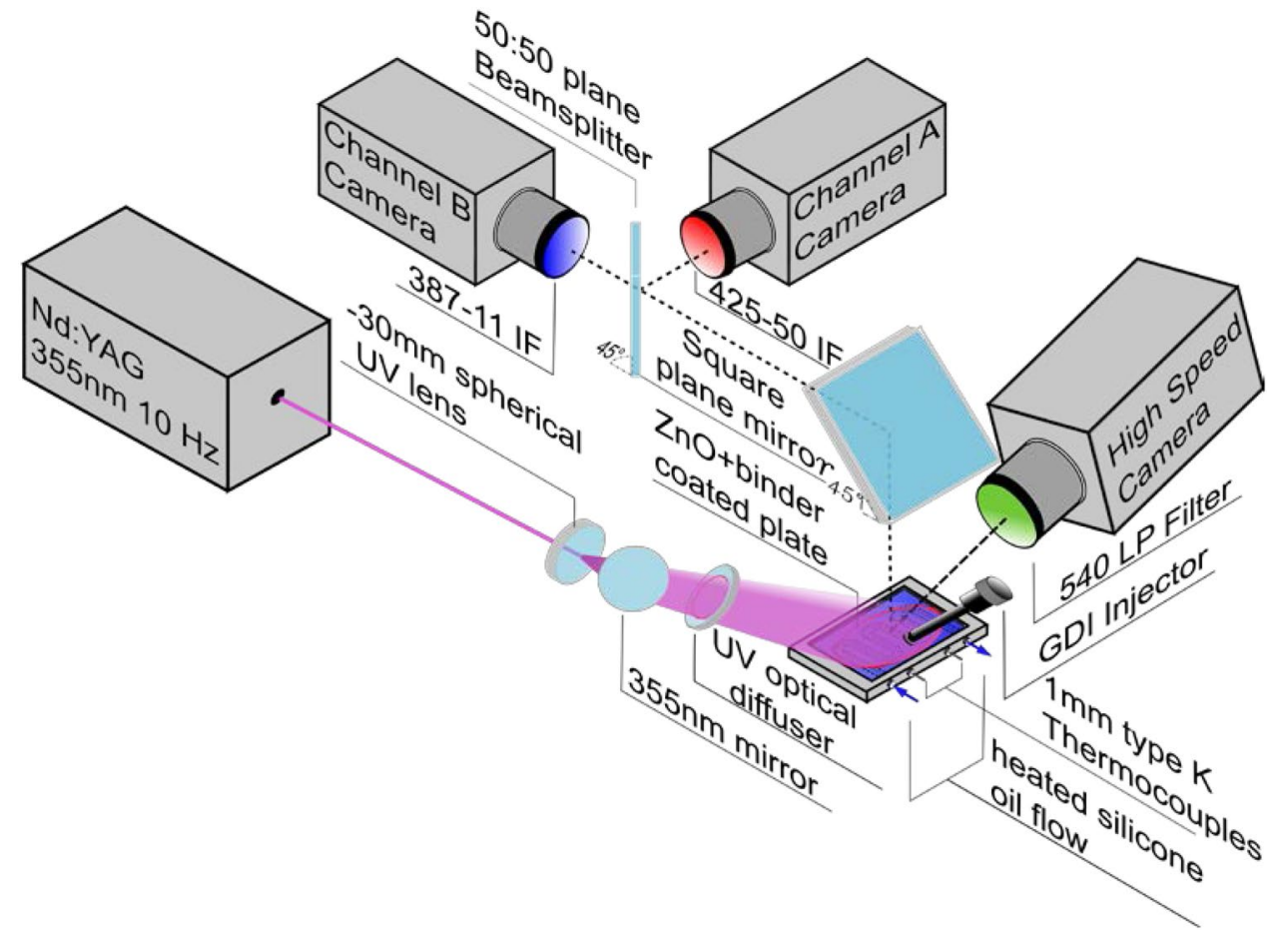

used to filter the luminescence emissions with the cameras with defined spectral band widths, which enable the extraction of a temperature-dependent intensity ratio (see Fig. 1). The two luminescence imaging cameras were aligned at the coated plate using a $45^{\circ}$ broadband square mirror (84-418, Edmund Optics) and a 50/50 beamsplitter (46,642, Edmund Optics) in the visible range. The two cameras were aligned using a PIV cross-correlation algorithm (DaVis 8.3, LaVision) based on the luminescence image achieving a resulting pixel displacement between the two channels of approximately 0.6 binned pixels.

\subsection{High-speed imaging}

To simultaneously visualise the spray-induced wall film and thereby correlate the position and extent of the liquid film with that of the surface temperature measurements, highspeed imaging was performed, see Fig. 2. For the visualisation of the liquid film, a CMOS high-speed monochrome camera (High-Speed-Star X, LaVision) in conjunction with a 50-mm Nikkor f/1.4 lens was used, obtaining a pixel scaling of the dewarped image of approximately $0.108 \mathrm{~mm} /$ pixel. A $540 \mathrm{~nm}$ long pass filter was used to block reflected laser light at $355 \mathrm{~nm}$ as well as any residual emissions from the second harmonic of the Nd:YAG laser. The sprayed wall film was illuminated using a focusable metal halide lamp (DLH400DT, max. $575 \mathrm{~W}$, Dedolight). Due to the broadband spectrum of the light source, a colour glass (OG515, Schott Glass) transmitting only above $500 \mathrm{~nm}$ was positioned in front of it to prevent illuminating the plate with light at shorter wavelength which could potentially interfere with the luminescence imaging cameras. The high-speed camera was aligned at a relatively steep angle regarding the coated plate to better visualise the transparent spray film on the surface, see raw images in Fig. 3a, b. Therefore, the images were dewarped using a calibration pattern and the commercial imaging software DaVis from LaVision. Note that $n$-hexane's spray film can be barely distinguished from the plate in the raw images. To improve the contrast of the liquid films on the plate and to extract them from the whole image, the first image prior to the injection was subtracted from the time series and a cut-off filter was used. Additionally a mask was applied to cut out the spray wall film from the images. The result of the applied processing steps can be seen in Fig. 3c, where the grayscale is inverted to improve the visibility.

\subsection{Calibration procedure and measurement uncertainty}

Prior to the calculation of the intensity ratio between the frames of the two cameras, three imaging pre-processing steps were performed. First, background subtraction followed by smoothing using a $7 \times 7$ pixels moving average filter was applied on the raw images resulting in a final resolution of aprox. $0.8 \mathrm{~mm}$. Afterwards, a cut-off filter at 50 pixel counts was run over the acquired luminescence images to remove areas with insufficient signal from the results.

As previously reported by Abram et al. (2015), the intensity ratio of $\mathrm{ZnO}$ for the two detection bands depends mainly 


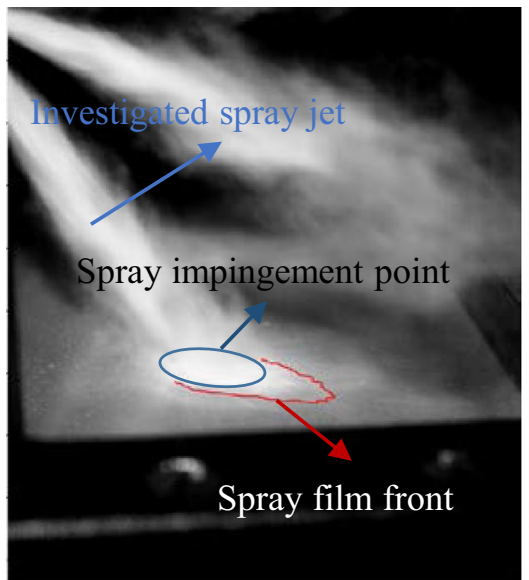

(a)

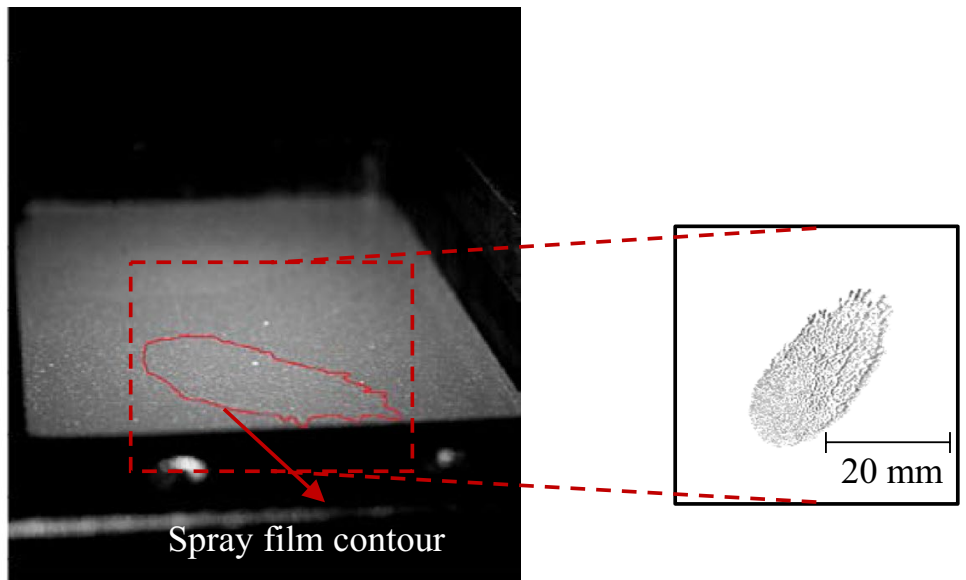

(b) (c)
Fig. 3 a High-speed image of the spray jet impinging on the steel plate, $1 \mathrm{~ms}$ after the start of injection (aSOI). b Image of the remaining liquid film at $8.8 \mathrm{~ms}$ aSOI and $\mathbf{c}$ processed image of the spray

on the temperature of the coated object but also on the laser fluence used to excite the $\mathrm{ZnO}$ particles. Figure 4a shows a clear effect of the laser fluence on the measured intensity ratio for $\mathrm{ZnO}$ at room temperature. Therefore, some influence of the shot-to-shot fluctuations of the laser pulse energy on the intensity ratio and thereby on the temperature measurements can be expected. To limit this undesired effect, the Nd:YAG laser was operated at relatively high lamp energy, which improved the shot-to-shot standard deviation of the laser pulse energy for the experiments to a value of around $2.5 \%$. Moreover, prior the measurement campaign, the laser was operated for one hour to reach relatively stable operating condition and thus avoid as much as possible drift of the laser pulse energy over time. Therefore, the effect of the film at $8.8 \mathrm{~ms}$ aSOI including dewarping, background subtraction and mapping with the luminescence images

shot-to-shot fluctuation of the laser fluence is considered to be relatively small, as it can be seen in Fig. 4b). The estimated standard deviation of the measured surface temperature due to the fluence variation is in this case around $0.6 \mathrm{~K}$ or $0.2 \%$. On the other hand, due to the nature of the laser beam Gaussian profile, the laser fluence is non-uniformly distributed over the coated plate. Although the laser beam was expanded using a spherical diverging lens $(f=-30 \mathrm{~mm})$ and a $5^{\circ}$ diffusion angle UV diffusor, the difference in the laser fluence between the central region and the corner of the imaged plate was as high as around 50\%, which led to significant spatial variations in the intensity ratio and hence in the indicated plate temperatures, as it can be seen in Fig. 5 . However, as this figure also shows, when the intensity ratios

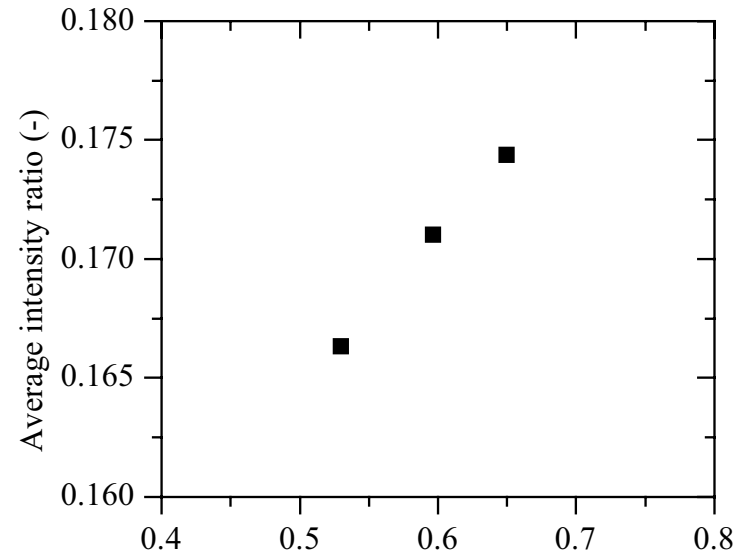

(a) Average laser fluence $\left(\mathrm{mJ} / \mathrm{cm}^{2}\right)$

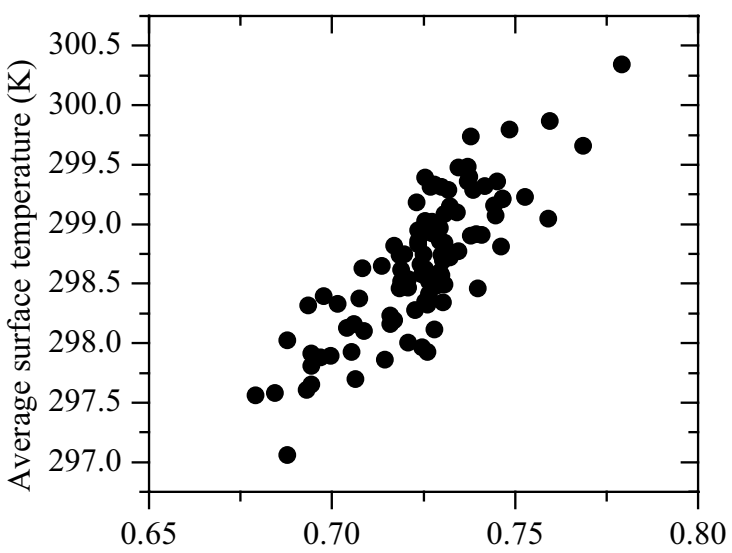

(b) Instantaneous laser fluence $\left(\mathrm{mJ} / \mathrm{cm}^{2}\right)$

Fig. 4 a Intensity ratio at different level of average excitation fluences and $\mathbf{b}$ scatter plot of single-shot indicated average surface temperature versus fluence for a fixed room temperature condition of $\sim 299 \mathrm{~K}$, showing the effect of shot-to-shot laser fluence variations 


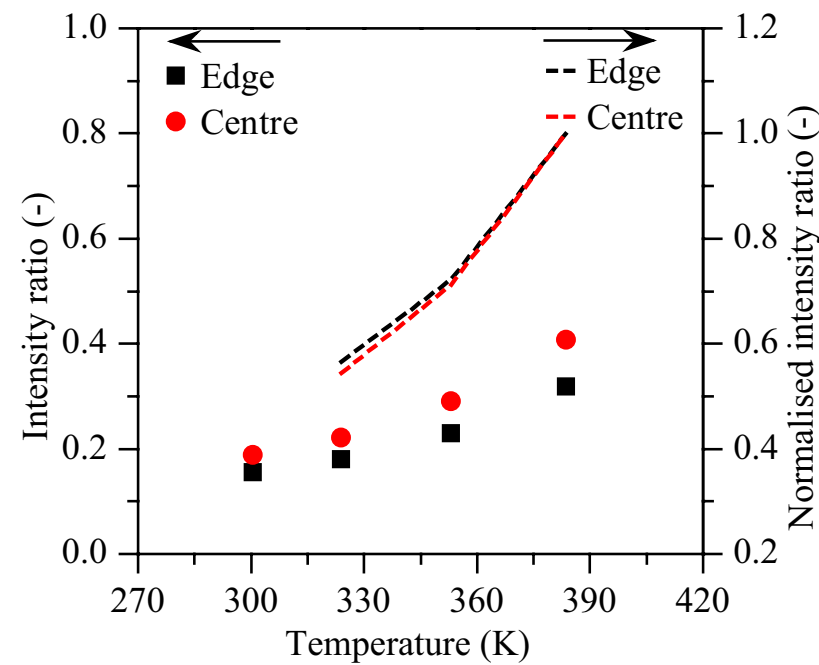

Fig. 5 Dependence of the intensity ratio (absolute and normalised) on the spatial distribution of the laser fluence for different spatially averaged temperatures $\mathrm{T}_{\mathrm{av}}$ at the centre and edge of the coated plate

in different regions are normalised by their respective values at room temperature, the resulting ratios show a very similar response to temperature. Therefore, the use of a socalled flat-field correction is necessary. For this purpose, a normalised average intensity ratio field over 100 images at uniform plate temperature, as this is the case with room conditions, can be used. The implications of this processing step are explained in detail in Abram et al. 2015. However, to shield the temperature field for drift in the laser fluence distribution during long-term measurements, white-field correction images were always acquired immediately prior to each injection.

To calculate the surface temperature from the measured intensity ratio between the two cameras, a calibration curve of the surface temperature as a function of this ratio needs to be obtained. For this purpose, 100 instantaneous image pairs were acquired at different stabilised plate temperatures ranging from room temperature (around $300 \mathrm{~K}$ ) to $393 \mathrm{~K}$, which represents the range of interest for this study. The plate temperature was monitored with the thermocouples shown in Fig. 2.

After processing the acquired images, as discussed in the previous paragraphs, the average intensity ratios for the calibration points were calculated and are plotted in Fig. 6. The calibration curve was obtained using a fit with a power law $T=a+b I R^{n}$, where $T$ and $I R$ are the temperature and intensity ratio respectively, and $a$ and $b$ the constants of the fit. The temperature sensitivity of the intensity ratio based on the fit function is also shown in Fig. 6 and lies between 0.5 and $2.3 \% / \mathrm{K}$ for the temperature range of interest. Therefore, the pixel-to-pixel precision (standard deviation), averaged over the 100 intensity ratio fields, and the shot-to-shot

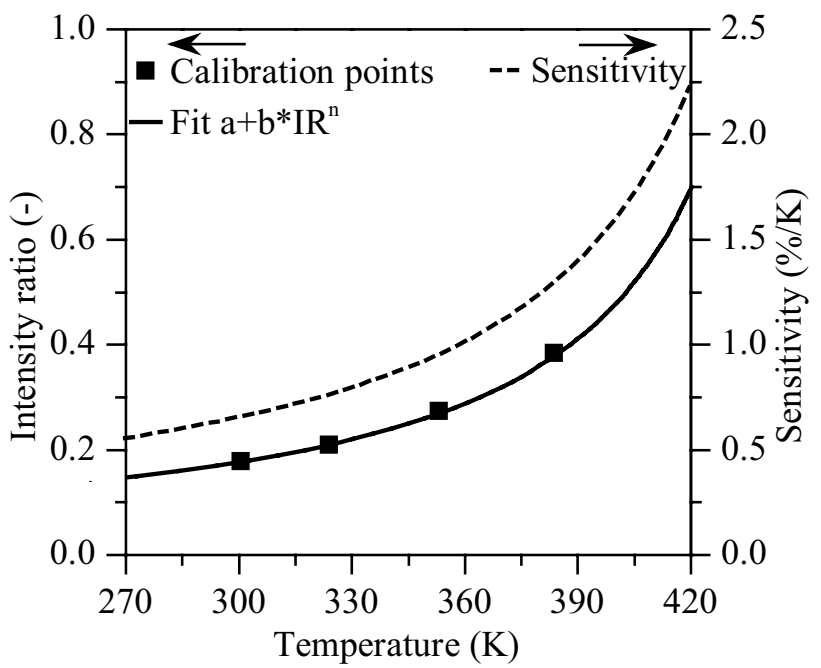

Fig. 6 Calibration curve and sensitivity $(1 / \mathrm{IR} \cdot \mathrm{d}(\mathrm{IR}) / \mathrm{d}(\mathrm{T}))$ of the surface temperature measurements for plate $A$ with an averaged thickness of $15 \mu \mathrm{m}$ coated with $\mathrm{ZnO}$ and binder with an average laser fluence of $\sim 1 \mathrm{~mJ} / \mathrm{cm}^{2}$

standard deviation of the mean surface temperature, decrease slightly with increasing plate temperatures. These are about 0.5 and $0.6 \mathrm{~K}$, respectively, at room temperature of $300 \mathrm{~K}$. At this point, it should be noted that a theoretical intensity ratio curve, derived from the spectra of bulk powder of $\mathrm{ZnO}$ in Fig. 1, leads to different intensity ratio values as a function of the temperature and so it cannot be used as an ex-situ calibration. Some of the difference can be attributed to the different physical state of the material between bulk powder and coating, leading to variations in the optical and thermal properties (which were discussed in Fond et al. (2015) and Abram et al. (2018) in the context of dispersed particles versus bulk powder) as well as interference from binder fluorescence. The knowledge of the spectral response of the various optical components is also not known with sufficient accuracy, in particular for non-collimated light and for the spectral range below $400 \mathrm{~nm}$. Future works will focus on strategies for ex-situ calibration in particular for application in industrial devices.

\section{Preliminary investigations}

\subsection{Influence of the annealing duration on the coating characteristics}

During some preliminary experiments, it was noted that for similarly coated plates a different annealing duration changed the intensity ratio measured with the same fluence and temperature. This phenomenon was investigated for three coated plates, keeping the same coating 
characteristics between them (same phosphor/binder concentrations and obtaining a thickness of around $36 \mu \mathrm{m}$ ) but varying the annealing time. Once coated, these plates were left in an oven for different periods of time varying between 3 and $48 \mathrm{~h}$ at $473 \mathrm{~K}$.

The luminescence intensity ratio from the coatings at a room temperature of around $300 \mathrm{~K}$, and the coating thickness were measured after each annealing procedure. The results are summarised in Table 2 and Fig. 7.

The results at these different stages, see Fig. 7, show that the annealing period plays a significant role in the luminescence characteristics of the coating. The increasing intensity ratio with annealing time and the fact that the coating thickness reduction, for plates $C$ and $D$, is practically the same despite the large difference in annealing time suggest that the phosphor material itself may be modified. Other works on other phosphors have also shown an influence of annealing or deposition temperature on the luminescence properties. For example, in Ranson et al. 1998, where the effects of annealing temperature and duration are investigated, the researchers showed that similar levels of luminescence between radio frequency (RF) magnetron sputtered $\mathrm{Y}_{2} \mathrm{O}_{3}$ :Eu thin films and thick sprayed films can be obtained by altering the annealing parameters. In Choy et al. 2011, emission-line sharpening and shift effects were observed to various extents at different deposition temperatures for electronassisted chemical vapour deposition (EACVD) $\mathrm{Y}_{2} \mathrm{O}_{3}: \mathrm{Eu}$ films. Considering that the binder can also be responsible to a certain extent for this change in the behaviour of coatings emission, further experiments need to be performed to fully assess these observations and to validate this reasoning. For certain applications such as when an engine is operated for a long period of time, the fact that the spectral characteristics of the phosphor coating may change in between the calibration procedure and the actual measurements could lead to notable uncertainties in temperature readings. Note that a $25 \%$ change in the intensity ratio corresponds to a $30 \mathrm{~K}$ change in the measured temperature in our case. However, for the plate temperatures of around $\sim 393 \mathrm{~K}$ investigated in this work and on the timescales of this application (up to around $6 \mathrm{~h}$ ), we found no noticeable differences in the intensity ratio

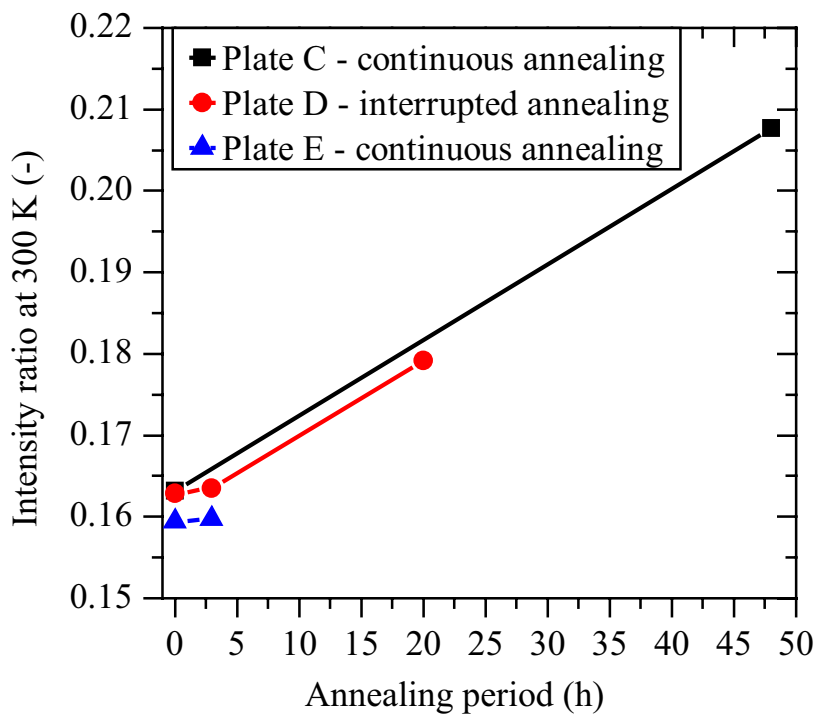

Fig. 7 Left: averaged intensity ratio variation with annealing duration for plates $C, D$ and $E$ taken at room temperature $(\sim 300 \mathrm{~K})$ with an averaged laser fluence of $0.78 \mathrm{~mJ} / \mathrm{cm}^{2}$ for 100 shots for each case

due to this effect during calibration and during actual measurements for the same temperature points.

\subsection{Stain formation}

In some of the preliminary experiments performed with $\mathrm{ZnO}$ and binder coatings, permanent changes in the room temperature luminescence intensity were observed in the location of the spray impingement before and after the injection. One example is shown on Fig. 8a, b, where an increase in intensity is observed on channel A (CWL $425 \mathrm{~nm}$ ) corresponding to the spray impingement region. Since no such intensity increase is observed on the other channel, the intensity ratio between the two channels is changed, with a higher indicated temperature at location of this "stain" of around $5 \mathrm{~K}$ as Fig. 8c shows. Note that these stains seem to occur randomly and for the performed experiments with the two plates $\mathrm{A}$ and $\mathrm{B}$, no significant alteration in the measured signal from the coated surfaces due to the contact with injected fuel could be noticed. Initial investigations suggest a dependence of the stain formation on the annealing period

Table 2 Annealing duration effect on the luminescence and thickness for similarly coated plates

\begin{tabular}{|c|c|c|}
\hline Plate & Annealing procedure & Observation \\
\hline $\mathrm{C}$ & $12 \mathrm{~h}$ of air drying at room temperature followed by a annealing period of $48 \mathrm{~h}$ at $473 \mathrm{~K}$ & $42 \%$ thickness reduction after annealing \\
\hline $\mathrm{D}$ & $\begin{array}{l}12 \mathrm{~h} \text { of air drying at room temperature followed by two subsequent annealing periods of } \\
3 \text { and } 20 \mathrm{~h} \text { at } 473 \mathrm{~K} \text { with a pause of } 3 \mathrm{~h} \text { in between }\end{array}$ & $\begin{array}{l}25 \% \text { thickness reduction after } 3 \mathrm{~h} \text { and a total } \\
\text { thickness reduction of } 41 \% \text { after additional } \\
20 \mathrm{~h}\end{array}$ \\
\hline $\mathrm{E}$ & $12 \mathrm{~h}$ of air drying at room temperature followed by a annealing period of $3 \mathrm{~h}$ at $473 \mathrm{~K}$ & $32 \%$ thickness reduction after annealing \\
\hline
\end{tabular}




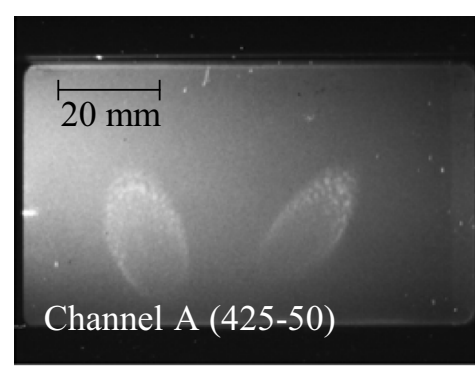

(a)

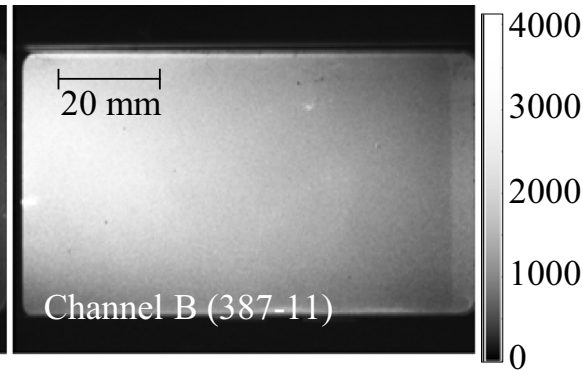

(b)

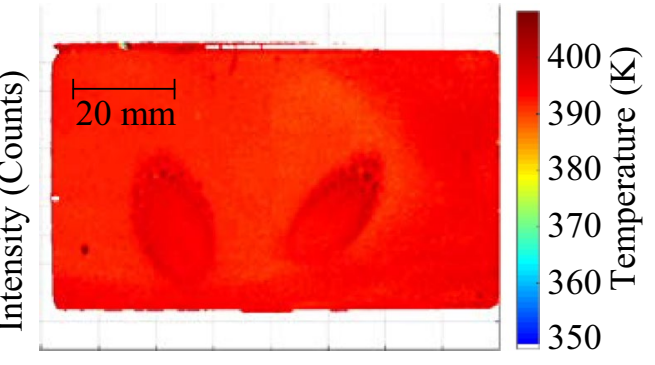

(c)
Fig. 8 a, b Influence of permanent stain formations from the injected fuel on the measured intensity by the two cameras for the ratio technique in the channels A (425-50) and B (387-11), respectively. These images show the result after several injections, made to a $1 \mathrm{~h}$ annealed plate, at a plate temperature of $393 \mathrm{~K}$. Such stains seem to occur randomly. c Effect of the stains on the calculated temperature field. Note that no stain formation could be noticed in the case of the plates A and B used for the measurements described in Sect. 4, thus having no influence on the measured temperatures of the coating as well as on the operating temperature during the experiments. The general trend, that could be observed, points to a less pronounced stain formation with lower plate temperatures during the investigation as well as with longer annealing periods. Note that the plate shown in the Fig. $8 \mathrm{c}$ had been annealed for only $1 \mathrm{~h}$ against $12 \mathrm{~h}$ for plates A and $\mathrm{B}$. No additional emissions could be detected from a plate coated only with binder without $\mathrm{ZnO}$, when multiple injections were performed at different temperatures. Only a weak signal with around 60 counts could be detected in the 425-nm channel coming from the binder itself. This value represents less than $5 \%$ of the averaged signal measured in channel A, and is otherwise already embedded in the calibration for different points, thus it is considered that it has no negative effect on the measurements. Abou Nada et al. (2016) noticed a change in the decay time of $\mathrm{ZnO}: \mathrm{Zn}$ based on the lubricant/phosphor mass ratio. Therefore, an effect of the fuel injected on the luminescence properties of the $\mathrm{ZnO}$ coating cannot be excluded. The actual cause for the change in the coating emissions could not be identified and, therefore, additional investigations are necessary to systematically avoid stain formation.

\section{Temperature measurements of the wall film cooling}

To investigate the viability of measuring surface cooling due to gasoline injection sprays using the intensity ratio method, a sequence of temperature measurements was performed at $10 \mathrm{~Hz}$ while one injection was performed. The results are shown in Fig. 9. Here, the steel plate A was heated up
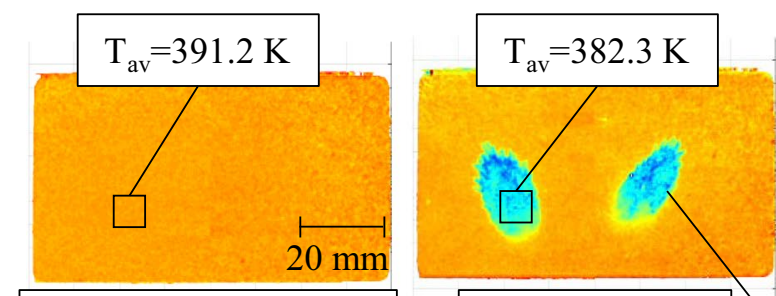

$\mathrm{t}=91.5 \mathrm{~ms}$ before $\mathrm{SOI}$

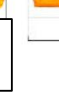

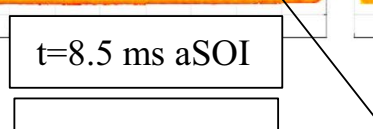
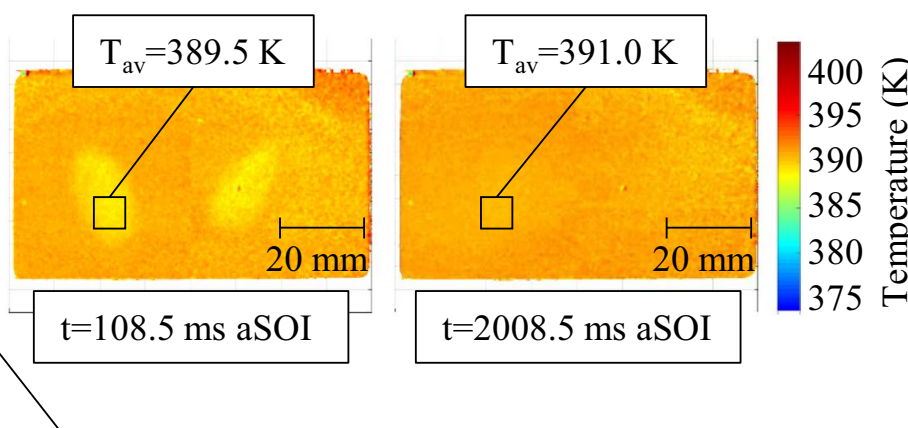

Spray wall film and the film contour

(high speed imaging)

Fig. 9 Surface temperature measurements for a plate temperature of $391 \mathrm{~K}$ and $n$-hexane at room temperature (around $300 \mathrm{~K}$ ). Top images correspond to the temperature fields with the liquid film contour depicted in black. Bottom image corresponds to the dewarped and isolated fuel film of the spray impinging on the right of the image. For the last two acquisition times no liquid film could be detected 
to $391 \mathrm{~K}$ and the first temperature field shows a uniformly distributed surface temperatures over the whole plate prior to the injection process. The second temperature field was acquired $8.8 \mathrm{~ms}$ after the start of injection (aSOI). Two distinct spots with lower temperatures can be observed on the plate's surface, after the two $n$-hexane spray jets impinged on the surface. To verify that the measured decrease in the surface temperature corresponds to the exact position and timing of the impingement, high-speed imaging of the spray wall film was also performed simultaneously and using the processing steps explained in Sect. 2, the film contour for the spray on the right was extracted from the high-speed images. In Fig. 9, it can be seen that at the time of the second temperature field recording, a liquid deposit still remains on the surface. The contour of the $n$-hexane spot was extracted and laid upon the corresponding temperature field in Fig. 9 and showing an accurate spatial overlap with the colder temperature region. It can be concluded that the temperature decrease in the two areas is the result of the spray impingement on the surface. Moreover, the average temperature decrease at $8.8 \mathrm{~ms}$ aSOI is around $9 \mathrm{~K}$ for the small squared area shown in Fig. 9. The third and fourth temperature fields shown in Fig. 9 were acquired at 108.5 and $2008.5 \mathrm{~ms}$ aSOI. Whereas in the subsequent shot at $108.5 \mathrm{~ms}$ aSOI a weak temperature decrease of $1.7 \mathrm{~K}$ can still be detected, the original surface temperature is completely restored at the last temperature field, again proving the functionality of the measurement technique for the sensing of the sprayinduced wall cooling. The reproducibility of the spray cooling is shown in Fig. 10 for three different injections with the same delay aSOI for the acquisition, where a delay of $2 \mathrm{~min}$ was set between injections to ensure the restoration of the initial plate temperature of around $363 \mathrm{~K}$. The maximum divergence of the spatially averaged temperature in the portrayed square area between injections is only $1.3 \mathrm{~K}$. Also, a third cold spot can be observed, which is caused by a partially impacting neighbouring spray jet. These measurements were performed in a separate measurement campaign during which the injector's position was slightly rotated leading to the partial impingement of a third spray on the plate.

For the measurements about $8 \mathrm{~ms}$ aSOI, liquid fuel is still present on the coated surface as evident from the high-speed visualisation shown in Fig. 9. To investigate the effect of a liquid film above the phosphor coating on the derived temperatures, measurements when both liquid and plate are at the same temperature, i.e. $300 \mathrm{~K}$, were performed.

Figure 11 shows three consecutive processed images taken with an acquisition frequency of $10 \mathrm{~Hz}$ at room temperature. The first temperature field (left) is taken prior to the injection process and shows a uniform temperature distribution. At $8.8 \mathrm{~ms}$ aSOI (middle), a slight temperature decrease of less than $2 \mathrm{~K}$ can be observed at the area of the liquid film. In this case, the plate temperature is far below the boiling temperature of $n$-hexane. However, some fuel evaporation of the liquid during the flight of the droplets and on the surface occurs, which may be responsible for the small cooling observed on the surface. After $100 \mathrm{~ms}$, a liquid deposit on the surface could still be detected with the high-speed visualisation, see Fig. 11, bottom. However, no significant change in the surface temperature at the area of the liquid fuel can be observed. Therefore, a negligible effect of the presence of liquid on the temperature measurements can be assumed.

Figure 12 illustrates the surface cooling of the coated steel plate (preheated and set at $391 \mathrm{~K}$ ) for four different acquisition times ranging from 3.8 to $11.8 \mathrm{~ms}$ aSOI. The temperature fields were acquired from separate consecutive injections with an increasing delay between the injection, and the laser pulse and camera exposure. At $3.8 \mathrm{~ms}$ aSOI, a well-pronounced liquid film could be detected and the
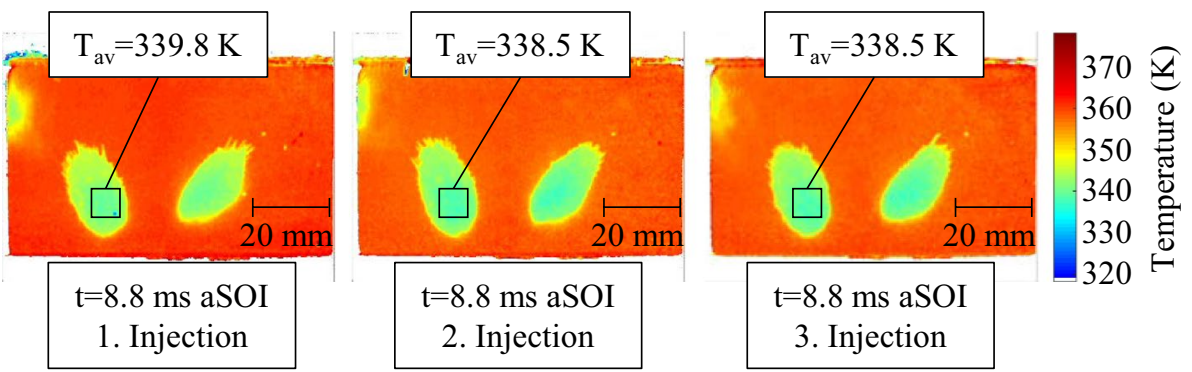

Fig. 10 Reproducibility of the injection process as well as of the resulting surface cooling. The sequence of images represents the temperature field at the same delay from start of injection for three consecutive injections (with the same parameters). Plate temperature was set to around $363 \mathrm{~K}$. A delay of two minutes is present between injec-

in the left upper corner of the temperature fields in Fig. 10, tions to ensure the restoration of the initially set plate temperature. All three temperature fields are obtained from data acquired with the same time aSOI. The repeatability of the experiment is showed by the maximum temperature difference of $0.7 \mathrm{~K}$ between injections

average temperature decrease in the selected area is around 
Fig. 11 Surface temperature measurements before and after injection when both the plate and the $n$-hexane fuel in the injector are at room temperature. Top images correspond to the temperature fields with the liquid film contour depicted in black. Bottom images correspond to the dewarped and isolated fuel film of the spray impinging on the right of the image

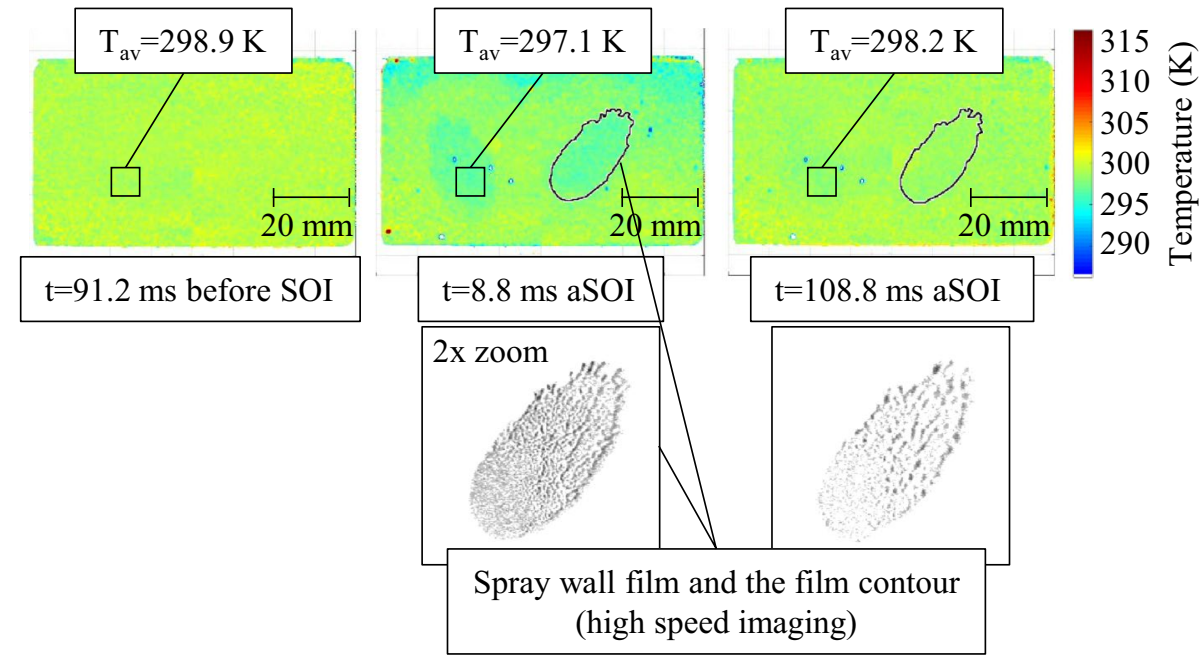

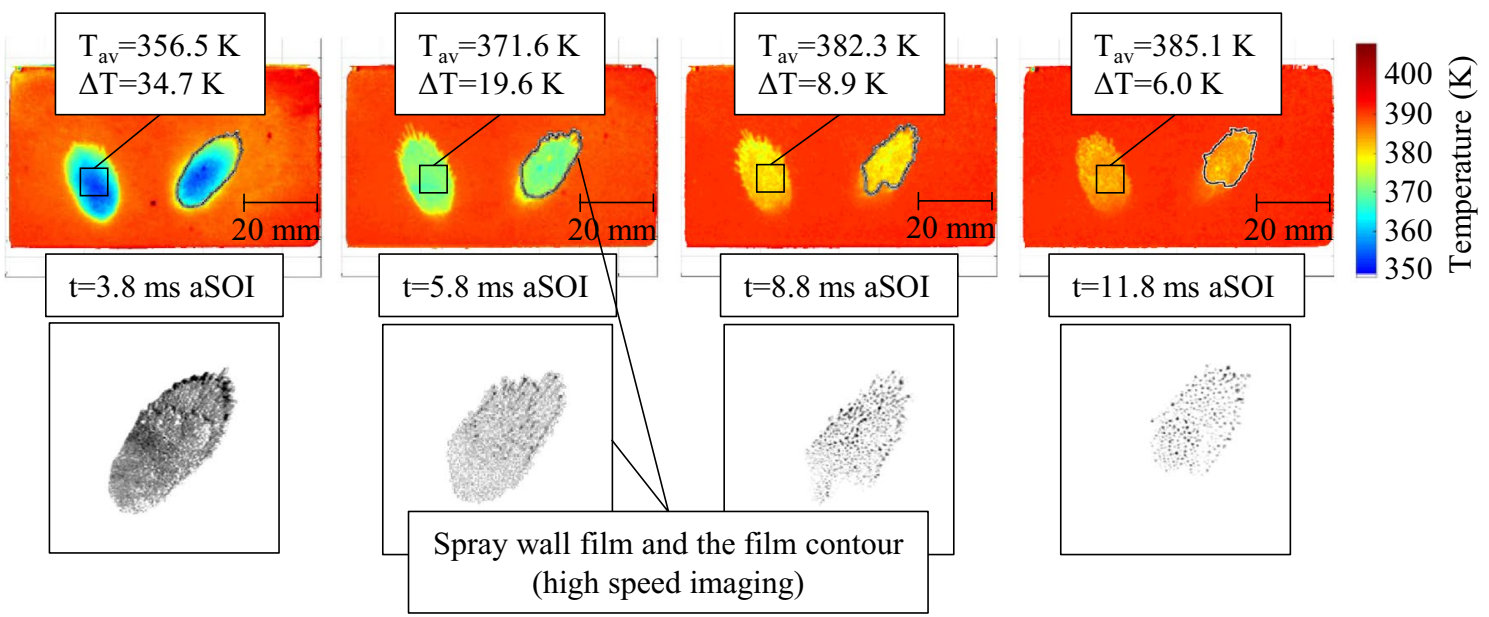

Fig. 12 Surface temperature fields at $391 \mathrm{~K}$ plate temperature and $n$-hexane at a room temperature of $300 \mathrm{~K}$ for different acquisition times aSOI derived from four separate injections with plate A.

$35 \mathrm{~K} .2 \mathrm{~ms}$ later the surface cooling is reduced almost by half to $20 \mathrm{~K}$. The sequence of images clearly shows the fast dynamics of the surface temperature cooling due to spray interactions and recovery due to conduction in the plate. At $11.8 \mathrm{~ms}$ aSOI, almost no remaining liquid on the surface of the steel plate could be detected with the high-speed imaging, whereas the imprint/pattern of the spray film can still be clearly observed in the temperature field. However, the temperature difference between the overall plate and the area of the spray impingement is only around $6 \mathrm{~K}$. Therefore, Figs. 11 and 12 clearly display that the intensity ratio technique in combination with $\mathrm{ZnO}$ provides sufficient precision to resolve the surface cooling phenomena resulting from the impingement of fuel sprays.
Top: temperature field images with the liquid film contour depicted in black. Bottom: high-speed imaging dewarped and isolated at the impingement area for the same instants

To investigate the influence of the coating thickness on the measured surface cooling, two plates with different coating thicknesses (plates A with $15 \mu \mathrm{m}$ and B with $31 \mu \mathrm{m}$ ) were tested. Figure 13 illustrates the temperature decrease as a result of the spray impingement on the two plates for different acquisition times aSOI for two plate thicknesses, where all measurement points represent individual injections. The reconstructed time series of surface cooling for both plate thicknesses show a well-defined trend, which indicates the good stability of the injection process parameters and the high measurement precision.

The recovery of the plate's surface temperature after the spray cooling is faster in the case of the thinner plate than for the thicker plate, see Fig. 13. This shows that the coating thickness has a noticeable effect on the surface 


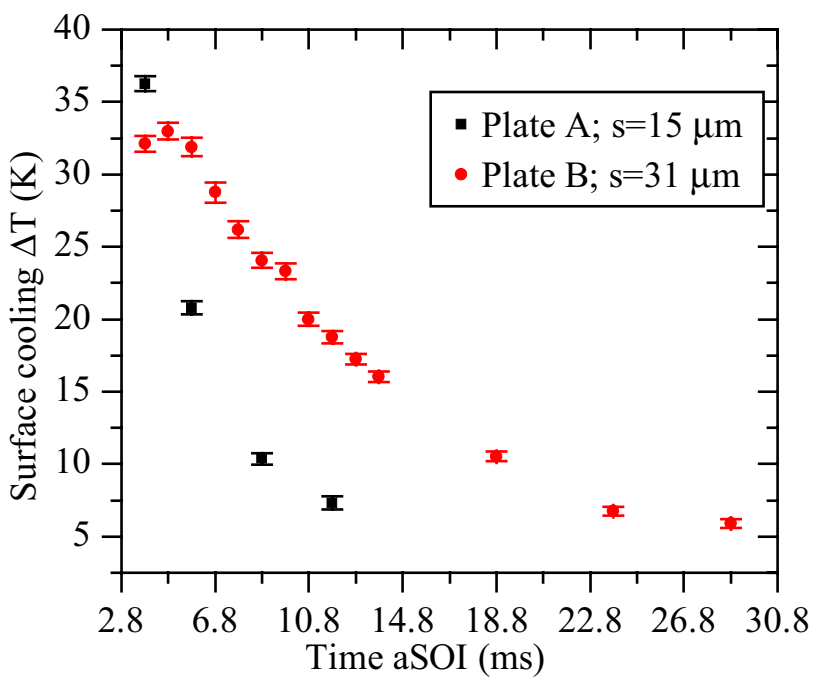

Fig. 13 Spatially averaged surface temperature decrease ( $T_{\text {av_bsoI }}-$ $\left.T_{\text {av_aSOI }}\right)$ as a function of the time aSOI for two plates with an average coating thickness of 15 and $31 \mu \mathrm{m}$. The spatially averaged temperature before injection $T_{\text {av bsOI }}$ is in both cases $391 \mathrm{~K}$. The $T_{\text {av_aSOI }}$ values correspond to the average temperatures in the squared areas shown in Fig. 12 and represent a separate fuel injection. The error bars represent the average spatial standard deviation of the 100 shots prior to the injection

temperature resulting from spray impingement. A thicker coating leads to slower conductive heat transfer rate from the metal plate to the front face of the coating, delaying the temperature recovery. The result is that for the same spray characteristics, the surface temperature stays colder for a longer time, which may help in resolving the post-cooling temperature recovery curve. Moreover, the stronger luminescence signal of the thicker coating is beneficial for the measurement accuracy. This can be useful to investigate smaller changes in the operating parameters as well as for qualitative studies of the effect of different parameters (injection duration, injection pressure, nozzle geometry, different fuels, binder properties, etc.) on the surface cooling. However, from our experiments we can see that the coating thickness plays an important role for precise quantitative analysis of the measured surface temperature as well as in case of heat transfer simulation validations. Therefore, detailed further investigation of the coating characteristics, e.g. thermal conductivity, exact coating thickness and heat capacity is necessary.

\section{Conclusions}

In this work, the feasibility of phosphor thermometry based on the intensity ratio method for temperature measurements of the wall cooling due to spray impingement was investigated. Accurate temperature measurements were obtained with the use of $\mathrm{ZnO}$ as thermal sensor, yielding spatial (pixel-to-pixel) and shot-to-shot standard deviations of, respectively, $0.5 \mathrm{~K}$ and $0.6 \mathrm{~K}$. Due to the high sensitivity of the $\mathrm{ZnO}$ phosphor, highly detailed reconstruction of the temperature gradients during the spray-wall impingement interaction can be made, where the detected temperature gradients represent spatially averaged values within the surface layer.

Furthermore, in the framework of the investigations, the presence of a liquid film (UV-grade $n$-hexane) on the coated surface had no considerable contribution to the detected luminescence from the coating and thereby no pronounced influence on the measured temperatures. However, any emission interferences from fuels with fluorescent properties need to be considered.

Due to the highly transient behaviour of heat transfer phenomena for this application, temperature measurements at the spray impingement area showed a significant influence of the coating thickness on the measured temperature history after spray impingement. Therefore, this factor needs to be considered for further quantitative analysis. However, for qualitative measurements as well as for simulation validations, a compromise between reduction of the coating thickness and measurement precision must be arrived at. In some cases, permanent stain formations at the spray impingement area could be observed resulting in a change in the intensity ratio. The tendency decreased with higher annealing duration time of the coated plates and also with lowering of the operating temperature of the plate during the experiments. Additionally, a notable dependency of the intensity ratio with the annealing duration has been identified. This effect should be taken into consideration, especially in cases where the phosphor coating is subjected to experiments that run for hours at temperatures similar or higher as the one used during the coatings annealing process.

Even though the intensity ratio technique has been challenged for its sensitivity and accuracy in surface thermometry in comparison with the decay time method, our experiments show high spatial and temperature precision and a similar accuracy to other phosphor surface thermometry experiments performed by time-resolved methods discussed in the introduction. Here, the main advantage lies in the fact that the measurement duration is below a microsecond. The results presented here show the viability and robustness of the method as well as the possibility of further applications, for example to in-cylinder temperature measurements and heat transfer phenomena analysis or other fast-paced surface heat transfer investigations. Moreover, a combination of such temperature measurements of the wall cooling and film thickness measurements, which were already demonstrated in the works of Henkel et al. (2016), Schulz et al. (2016), and Schulz et al. 
(2015), can help to understand the heat transfer induced by fuel impingement.

Open Access This article is distributed under the terms of the Creative Commons Attribution 4.0 International License (http://creativeco mmons.org/licenses/by/4.0/), which permits unrestricted use, distribution, and reproduction in any medium, provided you give appropriate credit to the original author(s) and the source, provide a link to the Creative Commons license, and indicate if changes were made.

\section{References}

Abou Nada F, Aldén M, Richter M (2016) Investigation of the effect of engine lubricant oil on remote temperature sensing using thermographic phosphors. J Lumin 179:568-573. https://doi. org/10.1016/j.jlumin.2016.07.058

Abram C, Fond B, Heyes AL, Beyrau F (2013) High-speed planar thermometry and velocimetry using thermographic phosphor particles. Appl Phys B 111:155-160. https://doi.org/10.1007/s0034 0-013-5411-8

Abram C, Fond B, Beyrau F (2015) High-precision flow temperature imaging using $\mathrm{ZnO}$ thermographic phosphor tracer particles. Opt Express 23:19453-19468. https://doi.org/10.1364/OE.23.019453

Abram C, Fond B, Beyrau F (2018) Temperature measurement techniques for gas and liquid flows using thermographic phosphor tracer particles. Prog Energy Combust Sci 64:93-156. https://doi. org/10.1016/j.pecs.2017.09.001

Aizawa T, Kosaka H (2008) Laser-Induced Phosphorescence Thermography of Combustion Chamber Wall of Diesel Engine. SAE International Journal of Fuels Lubricants 1:549-558. https://doi. org/10.4271/2008-01-1069

Bizzak DJ, Chyu MK (1995) Use of a laser-induced fluorescence thermal imaging system for local jet impingement heat transfer measurement. Int J Heat Mass Transfer 38:267-274. https://doi. org/10.1016/0017-9310(95)90013-6

Brübach J, van Veen E, Dreizler A (2007) Combined phosphor and CARS thermometry at the wall-gas interface of impinging flame and jet systems. Exp Fluids 44:897-904. https://doi.org/10.1007/ s00348-007-0446-4

Choy KL, Feist JP, Heyes AL, Su B (2011) Eu-doped Y2O3 phosphor films produced by electrostatic-assisted chemical vapor deposition. J Mater Res 14:3111-3114. https://doi.org/10.1557/ jmr.1999.0417

Claus RO, Beshears DL, Udd E et al. (1990) Laser-induced fluorescence of phosphors for remote cryogenic thermometry. 1370:365 https://doi.org/10.1117/12.24869

Fond B, Abram C, Heyes AL, Kempf AM, Beyrau F (2012) Simultaneous temperature, mixture fraction and velocity imaging in turbulent flows using thermographic phosphor tracer particles. Opt Express 20:22118-22133. https://doi.org/10.1364/OE.20.022118

Fond B, Abram C, Beyrau F (2015) On the characterisation of tracer particles for thermographic particle image velocimetry. Appl Phys B 118:393-399. https://doi.org/10.1007/s00340-014-5997-5

Fuhrmann N, Schild M, Bensing D et al (2011) Two-dimensional cycleresolved exhaust valve temperature measurements in an optically accessible internal combustion engine using thermographic phosphors. Appl Phys B 106:945-951. https://doi.org/10.1007/s0034 0-011-4819-2

Fuhrmann N, Brübach J, Dreizler A (2013a) Phosphor thermometry: A comparison of the luminescence lifetime and the intensity ratio approach. Proc Combust Inst 34:3611-3618. https://doi. org/10.1016/j.proci.2012.06.084
Fuhrmann N, Schneider M, Ding CP, Brübach J, Dreizler A (2013b) Two-dimensional surface temperature diagnostics in a fullmetal engine using thermographic phosphors. Meas Sci Technol 24:095203. https://doi.org/10.1088/0957-0233/24/9/095203

Goss LP, Smith AA, Post ME (1989) Surface thermometry by laserinduced fluorescence. Rev Sci Instrum 60:3702-3706. https:// doi.org/10.1063/1.1140478

Henkel S, Beyrau F, Hardalupas Y, Taylor AM (2016) Novel method for the measurement of liquid film thickness during fuel spray impingement on surfaces. Opt Express 24:2542-2561. https:// doi.org/10.1364/OE.24.002542

Husberg T, Gjirja S, Denbratt I, Omrane A, Aldén M, Engström J (2005) Piston Temperature Measurement by Use of Thermographic Phosphors and Thermocouples in a Heavy-Duty Diesel Engine Run Under Partly Premixed Conditions. 1. https://doi. org/10.4271/2005-01-1646

Kashdan JT, Bruneaux G (2011) Laser-Induced Phosphorescence Measurements of Combustion Chamber Surface Temperature on a Single-Cylinder Diesel Engine. 1 DOI 10.4271/2011-01-2049

Kleiber M, Joh R (2013) D3 Stoffwerte von sonstigen reinen Fluiden. VDI-Wärmeatlas. Springer, Berlin Heidelberg, pp 357-488

Knappe C, Andersson P, Algotsson M et al (2011) Laser-Induced Phosphorescence and the Impact of Phosphor Coating Thickness on Crank-Angle Resolved Cylinder Wall Temperatures. SAE International Journal of Engines 4:1689-1698. https://doi. org/10.4271/2011-01-1292

Krauss RH, Hellier RG, McDaniel JC (1994) Surface temperature imaging below $300 \mathrm{~K}$ using $\mathrm{La}(2) \mathrm{O}(2) \mathrm{S}: \mathrm{Eu}$. Appl Opt 33:39013904. https://doi.org/10.1364/AO.33.003901

Omrane A, Ossler F, Aldén M (2002) Two-dimensional surface temperature measurements of burning materials. Proc Combust Inst 29:2653-2659. https://doi.org/10.1016/s1540-7489(02)80323-6

Omrane A, Juhlin G, Aldén M, Josefsson G, Engström J, Benham T (2004) Demonstration of Two-Dimensional Temperature Characterization of Valves and Transparent Piston in a GDI Optical Engine. SAE Technical Paper 2004-01-0609. https://doi. org/10.4271/2004-01-0609

Panão MRO, Moreira ALN (2009) Intermittent spray cooling: A new technology for controlling surface temperature. Int J Heat Fluid Flow 30:117-130. https://doi.org/10.1016/j.jheatfluidflow .2008.10.005

Pfadler S, Beyrau F, Loffler M, Leipertz A (2006) Application of a beam homogenizer to planar laser diagnostics. Opt Express 14:10171-10180. https://doi.org/10.1364/OE.14.010171

Ranson RM, Thomas CB, Craven MR (1998) A thin film coating for phosphor thermography. Meas Sci Technol 9:1947

Reichelt L, Meingast U, Renz U (2002) Calculating transient wall heat flux from measurements of surface temperature. Int J Heat Mass Transfer 45:579-584. https://doi.org/10.1016/s0017 $-9310(01) 00157-0$

Schulz F, Schmidt J (2012) Infrared thermography based fuel film investigations 12th Triennial International Conference on Liquid Atomization and Spray Systems. Heidelberg, Germany, September 2-6

Schulz F, Schmidt J, Beyrau F (2015) Development of a sensitive experimental set-up for LIF fuel wall film measurements in a pressure vessel. Exp Fluids 56 https://doi.org/10.1007/s0034 8-015-1971-1

Schulz F, Samenfink W, Schmidt J, Beyrau F (2016) Systematic LIF fuel wall film investigation. Fuel 172:284-292. https://doi. org/10.1016/j.fuel.2016.01.017

Serras-Pereira J, Aleiferis PG, Walmsley HL, Davies TJ, Cracknell RF (2013) Heat flux characteristics of spray wall impingement with ethanol, butanol, iso-octane, gasoline and E10 fuels. Int J Heat Fluid Flow 44:662-683. https://doi.org/10.1016/j.ijheatflui dflow.2013.09.010 
Weickgenannt CM, Zhang Y, Lembach AN et al (2011) Nonisothermal drop impact and evaporation on polymer nanofiber mats. Phys Rev E Stat Nonlin Soft Matter Phys 83:036305. https://doi. org/10.1103/PhysRevE.83.036305
Yañez Gonzalez A, Pilgrim CC, Feist JP, Sollazzo PY, Beyrau F, Heyes AL (2015) On-Line Temperature Measurement Inside a Thermal Barrier Sensor Coating During Engine Operation. J Turbomach 137:101004-101004-101009. https://doi.org/10.1115/1.4030260 